\title{
Comment on supply chain risk management
}

\author{
A note on the paper \\ Hofmann, Erik: Risk management in international supply chains: the case of \\ natural hedging
}

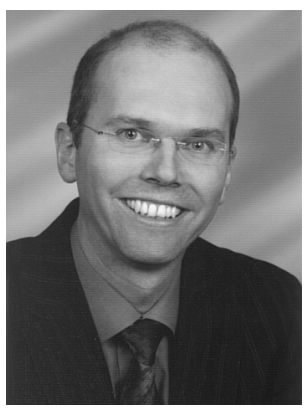

\section{Günter Prockl}

It is a common understanding that today's economies get more and more global. Companies for instance source their material and components increasingly on a global scheme (Trent/Monczka 2003). Others like automotive companies build and manage - together with their key suppliers - global production networks that span around the globe (Coe et al. 2008). Some authors even speak about a flat world (Friedman 2005) in which political, historical or geographical divisions are getting increasingly irrelevant, and where all the actors have equal opportunities as hierarchies and borders are diminishing. Unfortunately it seems however that this picture might be drawn way too optimistic. There are still borders in place and maybe the world is in fact even getting less flat (Stiglitz 2006) by simply transforming the business arena even for smaller companies now into a global setting, which is providing new unknown challenges of doing global business but which at the same time is also distributing the instruments and opportunities for handling these challenges unequal among the different players. In fact on a macro-economic level we can still see different levels of political and economic risks around the world. Current developments in northern Africa or Japan show how fast different parts of the world may change from a more or less stable situation into turbulence. But even the small changes are immediately expressed in the relative values of the different currencies. Markets are sensitive and the values of specific currencies are volatile. In consequence the single companies which are sourcing and dealing in global and international supply chains face new risks especially when it comes to the stability of the currency that build the baseline for the business contracts.

The paper of Erik Hofmann with the title "Risk management in international supply chains -The case of natural hedging" is going to address such topics of supply risks and the challenge of currency fluctuations for companies that source and deal globally. The objective is to discuss instruments of financial and natural hedging and their potential to reduce supply chain vulnerability in an international context. Different to existing contributions that are researching the topic mostly from the view of multinational enterprises (Chowdhry 1995; Duangploy/Helmi 2000; Kawaller 2008) this paper however is focusing especially on the small and midsized suppliers that have typically limited options of global hedging but at the same time often higher risks associated with the global business environment. Following suggestions of Calentey and Haugh (2009) or Kuwornu et al. (2009) an enterprise extending view is pursued, in which a large focal firm might take over certain risks of its smaller suppliers by hedging these risks on a broader scale and thus lower also the OEM's own risks of having suppliers that might run out of business. Such an allo- 
cation of specific tasks beyond the single enterprise reflects in its core the basic ideas of supply chain management. The cross-border value network mentioned in chapter 2.2 may thus be interpreted two-fold. It refers to international business and the related currency hedging across supply chain partners as well. Finally, the author also links the financial with the real physical aspects of supply chain management by stressing the concept of natural hedging. Natural hedging means in short that the focal firm, e.g. an OEM in the automotive industry, not only covers the financial aspects, by means of e.g. derivates, but also acts as the purchaser of the materials and hedges financial but also availability risks on the basis of real economic counter deals (Makar et al. 1999). This results however also in consequences regarding inventories, communication and transportation which come along with those transactions.

Such concepts of natural hedging appear interesting and relevant and they are not purely theoretical, as existing examples from real life industry already show. Automotive OEM for example buy occasionally steel for their suppliers to ensure the supplier's production capability (see also Devlin 2004 and Snyder/Ostle 2003 cited in the paper). The author is thus indeed well advised not to stress too much on the innovative character of the concept but to research with respect to a more formal analysis. His main goal is accordingly to illustrate the supposed key drivers of the natural hedging potential. The major intention is literally to provide a contribution to the concept evaluation on the basis of a cost-benefit or up-and-downside analysis. He thus tries to contribute to more profound decisions on when to apply the concept and when not.

For the formalization and the as well intended scenario analysis the value at risk method is used for the financial aspects of hedging and the physical aspects shall be assessed with respect to efficiency criteria. For the model building and the scenario analysis a number of specific assumptions are made and the supposed key drivers are modeled. Not all of these assumptions appear completely plausible, at least on the first view, and there remains also the question if all of the relevant drivers for ups and downs are yet included within the model. The author himself however mentions these potential deficits and explicitly understands the paper as a baseline for refinement and further discussion. Obviously like the reviewers, has the writer of this note the opinion, that such a discussion is worth to be held in front of a broader audience and that the suggested formalized model might provide a reasonable and useful basis for that.

With regard to the scenario analysis, major next steps should include a discussion of potential sensitivities with respect to the single assumptions. Unfortunately is the existing paper not providing very detailed information on the cost figures or the company characteristics that have been used for the scenario calculation. For a better foundation of the basic assumptions and the understanding of the basic relationships could it be of major interest, to know more about the behavior of the model when some of the underlying rough cut assumptions are systematically changed. The author mentions transportation distances and number of suppliers as potential candidates for such a variation. But are e.g. the pooling effects and discounts that the OEM realizes due to its company size really linear or do they decrease significantly when the purchasing volume exceeds a certain quantity. One could also ask if the suggested bundling effects in inbound transportation from the commodity supplier to the hedging OEM warehouse are not diminishing with increasing volume so that the additional costs for transportation to the SME supplier, which result from the natural hedging, might be even higher than modeled in the existing description. Is it 
then for instance thinkable to have situations where there is never an intersection between the curves that are describing the ups and downs? This might be related to the question on what the result of having a need for high volumes that are favorable in the context of natural hedging really means. In other words is the concept really applicable to support small and midsized suppliers that do not have this high values or eat the additional communication and transaction costs factually all the potential benefits up.

This leads also to other issues that provide a broader platform for further research. As already mentioned, researches Hofmann the topic of hedging from the viewpoint of a supply chain instead of that of a multinational enterprise. Such a company extending focus makes it especially interesting but also raises almost instantly the topics of cooperation and coordination which are typical for the extended supply chain in general. Such questions might go way beyond the modeled hedging fees and the ascribed motivation of the OEM to secure its own inbound streams by helping the suppliers. It touches topics of dependency, trust and unwanted transparency about purchasing volumes and purchasing prices among contract partners and their linkages for instance to the necessary fee level. It also touches on coordination issues and the necessary transparency for planning the hedging activities among the supply chain actors to avoid phenomena like phantom orders, putative shortages and resulting bullwhip effects that sometime occur in practice when "natural hedging" is applied in an unsystematic manner. In other words, with respect to hedging there might be on the one hand a lot more downs to model and maybe also some prohibitive downs to discuss that are present when applying the concept to a supply chain instead of to enterprises that are bound under a single governance scheme. On the other hand it might be as well an interesting question to go even deeper; especially into that specific supply chain topic. So far the paper describes a supply chain situation in which the market power is unequally distributed among a focal company and its supplier base. It would be interesting to analyze, if financial and natural hedging could also be a practice for supply chains in which there is no such dominant focal firm available. The question would then be, if it is for instance possible, to quasi shift the risk from the level of the single actors to the superior network level of the supply chain, and what restrictions and conditions would apply for such new and at the same time old cooperative forms of unbundling and re-bundling of company functions in a supply chain environment.

\section{References}

Caldentey, R./Haugh, M.B. (2009): Supply contracts with financial hedging, in: Operations Research, Vol. 57, No. 1, pp. 47-65.

Chowdhry, B. (1995): Corporate Hedging of Exchange Risk When Foreign Currency Cash Flow Is Uncertain, in: Management Science, Vol. 4, No. 6, pp. 1083-1090.

Coe, N., et al. (2008): Global production networks: realizing the potential, in: Journal of Economic Geography, Vol. 8, No. 3, pp. 271-295.

Devlin, G. (2004): Wall Street risk tools applied to automotive supply chain, in: MSI Manufacturing Systems, Vol. 22, No. 12, p. 9.

Duangploy, O./Helmi, D. (2000): Foreign currency hedge accounting: multi-currency versus functional currency accounting, in: Managerial Auditing Journal, Vol. 15, No. 3, pp. 232-246.

Friedman, T. (2005): The World Is Flat: A Brief History of the Twenty-First Century, London. 
Kawaller, I. (2008): Hedging Currency Exposures by Multinationals: Things to Consider, in: Journal of Applied Finance, Vol. 18, No. 1, pp. 92-98.

Kuwornu, J.K.M., et al. (2009): Agency problem and hedging in agri-food chains: Model and application, in: Journal of Marketing Channels, Vol. 16, No. 3, pp. 265-289.

Makar, S.D., et al. (1999): The management of foreign currency risk: derivatives use and the natural hedge of geographic diversification, in: Accounting \& Business Research, Vol. 29, No. 3, pp. 229-237.

Snyder, J./Ostle, D. (2003): For now, Germans are protected from impact of strong Euro, in: Automotive News Europe, Vol. 8, No. 10, p. 1.

Stiglitz, J. (2006): Making globalization work, London.

Trent, R./Monczka, M. (2003): Understanding integrated global sourcing, in: International Journal of Physical Distribution \& Logistics Management, Vol. 33, No. 7, pp. 607-629.

Günter Prockl, Prof. Dr., ist Associate Professor am Department of Operations Management der Copenhagen Business School.

Anschrift: Copenhagen Business School, The Department of Operations Management, Solbjerg Plads 3, B.5.24, DK-2000 Frederiksberg, Tel.: +45 (0)3815-2474, Fax: +45 (0)3815-2440, E-Mail: gp.om@cbs.dk 